OAI-PMH: http://www.indteca.com/ojs/index.php/Revista Scientific/oai

Ensayo Original / Original Essay

\title{
La Práctica Docente Universitaria desde la Perspectiva de la Dialogicidad y las Relaciones de Poder
}

Autora: Noris Evelin Duque Zambrano Universidad Nacional Experimental Simón Rodríguez, UNESR norisduquezambrano@gmail.com Mérida, Venezuela

\section{Resumen}

El siguiente ensayo muestra una reflexión referida a la práctica docente universitaria desde la perspectiva de la dialogicidad y las relaciones de poder partiendo del hecho que el sistema educativo universitario requiere de nuevas formas de concebir las relaciones de poder presentes en el sistema de formación que tiene lugar en la práctica docente universitaria. Lo que significa, mirar esta práctica desde otra perspectiva de pensamiento: una práctica comprometida, abierta de sí y del mundo, guiada por la dialogicidad que posibilite la creación de espacios y procesos de aprendizaje que promuevan la interacción y la aceptación de las diferencias del otro desde una perspectiva de horizontalidad que rechaza las verticalidades del encuentro entre docentesestudiantes, a partir del diálogo como eje esencial de la práctica docente. educación.

Palabras clave: práctica pedagógica; relación profesor-alumno; 


\section{The University Teaching Practice from the Perspective of Dialogicity and Power Relations}

\section{Abstract}

The following essay shows a reflection referring to university teaching practice from the perspective of dialogicity and power relations, starting from the fact that the university education system requires new ways of conceiving the power relations present in the training system that takes place in university teaching practice. This means to look at this practice from another perspective of thought: A commited practice open to itself and the world, guided by the dialogicity that allows the creation of spaces and learning processes that promote the interaction and acceptance of the differences of the other from a horizontal perspectivethat rejects the verticalities of the encounter between teacher and students, from the intersubjective dialogue as an essential axis of the teaching practice.

Keywords: teaching practice; student teacher relationship; education.

Date Received: 10-04-2018

Date Acceptance: 23-06-2018 


\section{Introducción}

Pensar la práctica docente desde lo dialógico y las relaciones de poder implica que el docente universitario tenga presente que el estudiante asume un determinado modo de enfrentarse al mundo para establecer relaciones con el otro (en este caso) con sus pares, con el docente, y de lo otro la universidad; así mismo accede a un determinado modo de comportarse, esto significa entender a la práctica docente como una manera de dialogo, por cuanto la conversación entre docentes y estudiantes es sin duda necesaria para que tenga lugar el encuentro entre ambos. Así, el docente acepta la voz del estudiante como parte de su dialogo interior y convierte esa voz exterior en habla interna, es decir el docente ha de decirse así mismo lo que esa voz le ha dicho desde afuera y prolongar su significado.

Por otra parte, en las relaciones de poder presentes en la práctica docente, se generan una sucesión de actos lingüísticos, cada uno de los cuales es un mensaje (dice algo al estudiante), estructurado según un léxico y una sintaxis. Estamos ante un discurso que adopta una forma específica de acto de habla, cumple una función, implica una actitud por parte del hablante, acompañada de algunas pretensiones de verdad.

Es en este contexto, en el que pretendo desplegar este ensayo que intenta visualizar la práctica docente desde la perspectiva de la dialogicidad y su vinculación con las relaciones de poder y así entender, partiendo del hecho que el sistema educativo universitario requiere de nuevas formas de concebir las relaciones de poder presentes en el sistema de formación que tiene lugar en la práctica docente universitaria. Así mismo, busco interpretar cómo la universidad tiene entre sus objetivos sujetar al individuo al proceso de producción que habrá de garantizar la construcción de conocimiento. De allí, la importancia de abordarla dialogicidad y las relaciones de poder como dos dimensiones de un mismo movimiento desde una perspectiva crítica- reflexiva. 


\section{Desarrollo}

En la práctica se produce una dificultad por parte del docente para mantener la capacidad del diálogo cuando éste considera que sólo él puede hablar y su discurso debe ser respetado y aceptado. En este sentido, la incapacidad para el diálogo está en el docente, y siendo este de acuerdo con Gadamer (2000a):

El auténtico transmisor de ciencia, esa incapacidad radica en la estructura monologal de la ciencia y de la teoría moderna. Se ha intentado una y otra vez en la vida universitaria aliviar la clase con el debate y entonces se ha hecho la experiencia contraria: es sumamente difícil pasar de la actitud receptiva del oyente a la iniciativa de la pregunta y la oposición, y rara vez tiene éxito. Hay en definitiva en la situación docente, cuando se amplía más allá de la intimidad de una conversación en el pequeño círculo una dificultad insuperable para el diálogo (págs. 207-208).

A mi modo de ver, la mayoría de los sistemas educativos están pensados de tal forma que la figura del docente se entroniza es así como, éste es quien tiene el mayor turno de palabra y muchas veces asume una posición de dirección y control dejando de lado su papel mediador en el proceso enseñanza-aprendizaje, al convertir el aula de clase en un espacio monologal con poca o nula interacción con los estudiantes, que le impide prestar atención a las experiencias y vivencias en la construcción de saberes centrándose en una práctica caracterizada por la transferencia de conocimientos y la repetición, que impide la formación de sujetos con compromiso social capaces de transformar la sociedad de la que forman parte.

En este sentido, si el sistema educativo se basa principalmente en la racionalidad instrumental para transmitir los conocimientos y son los docentes quienes deciden qué, cómo y cuándo se aprende estaríamos en presencia de lo que denuncia Freire (2008a), en su concepto de "educación bancaria" cuando manifiesta que: 
...siempre que se considere el futuro como algo dado de antemano, ya considerándolo como una pura repetición mecánica del presente, con cambios apenas adverbiales, ya porque será lo que tenía que ser, no hay lugar para la utopía, es decir para el sueño, para la opción, para la decisión para la espera en la lucha, única en que existe esperanza. No hay lugar para la educación, sólo para el adiestramiento (pág. 117).

En un intento por avanzar en esta propuesta defiendo la idea de desmontar la figura del docente entronizado por un sujeto docente capaz de conversar, escuchar con atención al estudiante para favorecer el dialogo sustentado en bases sólidas y en un clima de respeto, inclusive si están presentes intereses de poder. Así lo corrobora Gadamer (2000b): cuando plantea que: "El hacerse capaz de entrar en diálogo a pesar de todo es la verdadera humanidad del hombre" (pág. 29). Entonces, lo importante es comprender en las relaciones de poder presentes en la práctica docente la discursividad e intersubjetividad y reconocer las posiciones que tanto el sujeto docente como el sujeto aprendiz ocupan en la situación dialogal.

Esto implica, examinar la manera en las que el discurso desempeña un papel dentro del sistema estratégico en el que las relaciones de poder entre el docente y el estudiante están implicadas. De este modo, se requiere de la experiencia dialogal para establecer relaciones con el otro, en particular con el estudiante al interior del aula universitaria, convirtiéndose ésta no solo en un espacio físico lo más importante en el ambiente dialogal, en la que oyente y hablante busquen comprensión y entendimiento. Rescatamos de Freire (2008b), la visión dialógica al asumirla como:

....un fenómeno humano por el cual se nos revela la palabra, de la que podemos decir que es el diálogo mismo. Por ello hay que buscarla palabray sus elementos constitutivos. Descubrimos así que no hay palabra verdadera que no sea una unión inquebrantable entre acción y reflexión y, por ende, que no sea praxis. De ahí que decir la palabra verdadera sea transformar el mundo (pág. 37). 
Desde esta perspectiva, se debe reconocer que el ser humano es dialógico por naturaleza y que existe sólo en relación continua con otros, quienes se encuentran para la transformación del mundo en colaboración. De allí, que este diálogo ha de estar impregnado de reflexión, acción y crítica convencidos de que solo es posible construir conocimiento a través de la experiencia y la comprensión de procesos para la solución de problemas. Así, estudiantes y docentes se ocupan de manera conjunta como participantes activos en la construcción de saberes.

En la práctica docente la dialogicidad y las relaciones de poder a mi modo de ver representan dos dimensiones de un mismo movimiento al que se le intenta en este ensayo dar esclarecimiento desde una perspectiva críticareflexiva lo que permite la posibilidad de comprenderlas en el contexto universitario, temáticas que han sido estudiadas de manera profusa por diferentes autores en las últimas décadas del siglo XX y en el siglo XXI. Sin embargo, éstas han sido escasamente desarrolladas de manera articulada.

En el entendido, de no quedarse en el análisis del lenguaje, es necesario abrir nuevos horizontes, desde la vinculación dialogicidad y relaciones de poder en el ámbito universitario, ambas están presentes de manera particular en el proceso enseñanza aprendizaje. De allí que, es conveniente asumirlas en un solo horizonte que enriquezca el comprender humano de lo que significa la práctica docente. Sin embargo, otra vinculación que se establece en la práctica docente es la relación poder- saber.

Para profundizar la idea, es conveniente destacar que el docente utiliza diferentes instrumentos de evaluación que contribuyen a afianzar su poder en el aula de clase. Uno de ellos, lo constituye la aplicación del examen escrito para medir el nivel de conocimiento de sus estudiantes. Al respecto, Hoskin (2001): señala que "El examen es, entre todas las técnicas, la más obviamente educativa, más incluso que la disciplina, que suele ser superficialmente mal interpretada como técnica exclusiva de poder y control. Ambas deben 
considerarse como técnicas de poder-saber" (pág. 35).

Esto hace referencia a que está técnica de evaluación se ha extendido y ha mantenido su poder no sólo en el contexto educativo sino en otras ciencias humanas de conocimiento como la psiquiatría utilizándose como un mecanismo de dominación donde los poderosos dominan al impotente. De allí que, urge la necesidad de reconocer y comprender la evaluación como un proceso continuo, concebido como un momento de reflexión y crítica donde el aprendiz se constituya como sujeto ya que vista como caso contrario su efecto es la multiplicación de los lazos de sujeción y una práctica en el que el estudiante es tratado como una persona a la que se le aplican un conjunto de normas cuya finalidad es obtener información para hacer juicios de valor, a partir de criterios de eficiencia.

Dentro de ese marco de referencia, existen sospechas de que la construcción de saberes muchas veces es el resultado de relaciones de poder, es decir, normas y disciplina como formas de estimular la producción por parte de los estudiantes y disposición para alcanzar los objetivos del curso. En este contexto, es conveniente destacar que se continúa haciendo lo expresado por Jaeger (1980): cuando señala, "la paideía es el proceso por el cual las generaciones adultas buscan formar en el sentido de dar forma en las más jóvenes el ideal de hombres que ellas mismas quisieron llegar a ser" (pág. 5). Pudiera entenderse que en este proceso, el docente es quien modela y el estudiante es la materia a la que se da forma; el docente es quien posee la verdad y la transmite al estudiante, le indica la norma a seguir porque tiene el control. Desde esta mirada, se limita la creatividad y la postura de los estudiantes ante el proceso educativo del cual es parte fundamental.

Sin embargo, es preciso comprender que tiene lugar una asimetría, una donde el estudiante pretende construirse a sí mismo para enfrentar un futuro diverso e incierto y por el otro un docente que pretende defender su postura, su verdad en detrimento de la construcción de saberes coherentes con las 
necesidades de la sociedad actual. Esta situación, implica la necesidad de cambios estructurales en la práctica del docente de quien se espera mayor sensibilidad humana capaz de favorecer el dialogo y la construcción de saberes.

Aquí nos damos cuenta de la necesidad de generar cambios importantes en las teorías y las formas de poder que tienen lugar en las universidades donde muchas veces se utiliza el poder como saber único, dador de conocimientos. En palabras de Gil (2007):

...muchos docentes universitarios dejan "fluir" sus carreras académicas prestando más atención al cómo que al por qué y al para qué, ignorando de manera supina los fundamentos epistemológicos y gnoseológicos que deben ser clave en el mundo de las aulas (pág. 78).

Podría entenderse que esta situación descrita atentaría contra la creatividad, posibilitaría el autoritarismo patriarcal, y mantendría a distancia las pretensiones de validez del estudiante, impidiéndole pensar y comprender el proceso de manera reflexiva Es así, que desde esta visión una transformación en la práctica docente desde las relaciones de poder, requiere de una nueva forma de ver la autoridad, el examen y la memorización en la que docentes y estudiantes busquen comprensión y entendimiento a partir de procesos dialógicos.

\section{Conclusiones}

Desde asuntos como los indicados, repensar la práctica docente desde la dialogicidad y las relaciones de poder, implica ser pensada desde un horizonte que favorezca, el cultivo de habilidades como de disposiciones que conducen a una conducta reflexiva y razonable. Esto es posible, a partir de

defender la experiencia dialógica como un proceso que propicia la comunicación, la naturalidad de la pregunta y la respuesta basada en el 
diálogo intersubjetivo que permita superar la incapacidad para el diálogo.

De allí que, es necesario abrir espacios para la creatividad, la inventiva, el desarrollo de todas las potencialidades del individuo para ser capaz de soñar, de expresar sus sentimientos y creer que se puede construir saberes de forma colectiva a partir de sus vivencias y experiencias. De allí que, un aprendizaje a partir del diálogo en el aula de clase requiere necesariamente de diversos mecanismos que posibiliten la construcción del saber universitario desde una mirada más humana y social que necesita de un docente comprometido en generar espacios en el aula de clase donde se privilegie la interacción y el diálogo como formas de compartir saberes, experiencias y vivencias.

Es conveniente rescatar el diálogo como aquel capaz de crear espacios reflexivos para comprender el mundo y las distintas realidades que se muestran en el aula de clase, donde surja el acto de preguntar, que invita a los estudiantes a asumir una postura crítica y reflexiva en la construcción de saberes a partir de procesos de interpretación y comprensión de significados. Por lo tanto, urge el encuentro con el otro que da apertura a la reflexión y acción en una relación amorosa caracterizada por el compromiso, humildad y responsabilidad de los involucrados en el acto de enseñar y aprender.

De aquí se desprende que la relación de poder se puede ejercer sobre los aprendices en tanto que constituyen de acuerdo con Foucault (1998): "una especie de entidad biológica que se debe tomar en consideración, si queremos utilizar estos (aprendices), para producir" (págs. 245-246). Con ello admitimos que la función del poder no es esencialmente la de prohibir, sino la de producir, en nuestro caso: producir conocimiento. Se trata de entender que en la práctica docente se presentan relaciones de poder particulares que tienen características y autonomía propia. 
De esta manera, el estudiante presenta dificultades para construir conocimientos sin considerar los poderes sociales presentes en los procesos de interacción con sus pares, en especial la que se genera con el docente en el aula de clase. Es así como, aun cuando no se utiliza el castigo físico en el desarrollo de los procesos enseñanza aprendizaje el docente asume muchas veces una posición vigilante de las actividades con la intención de alcanzar sus objetivos y lograr un mayor rendimiento y productividad en los estudiantes.

Desde esta mirada, estamos llamados a repensar la importancia que tiene la creación de escenarios de aprendizaje que promuevan el diálogo, la reflexión, la crítica, la creatividad y la participación de docentes y estudiantes dispuestos a construir saberes a partir de las experiencias y vivencias de los actores educativos que posibilite la formación de individuos críticos, creativos, con valores, ciudadanos que contribuyan en la construcción de una sociedad más comprometida con el desarrollo humano de este mundo.

Aquí la situación que está en juego es una nueva manera de ser docente, una invitación a pensar desde otras lógicas, de otras formas de ser y estar en el mundo; que implique proyectar otra mirada sobre la universidad que dé a los estudiantes espacios para que intervengan de otra manera en su propia formación, lo que daría un nuevo sentido a practicar juntos, estudiantes y docentes, un pensamiento reflexivo como ejercicio crítico.

\section{Referencias}

Foucault, M. (1998). Vigilar y castigar: Nacimiento de la prisión. ISBN 10: 9682301173; ISBN 13: 9789682301179. México: Siglo XXI Editores, págs. 314.

Freire, P. (2008a,b). Pedagogía de la esperanza. Un reencuentro con la pedagogía del oprimido. Buenos Aires, Argentina: Siglo XXI Editores. Gadamer, H. (2000a,b).Verdad y Método II. Salamanca, España: Sígueme. Gil, R. (2007). Perspectivas de la educación superior en Venezuela en un 
mundo globalizado. ISBN: 978-980-11-1043-9. Mérida, Venezuela: Universidad de Los Andes, págs. 233.

Hoskin, K. (2001). Foucault a examen. El criptoteórico de la educación desenmascarado. En S.J. Ball (Comp.). Madrid. España: Morata. Jaeger, W. (1980). Paideia: Ios ideales de la cultura griega. México: Fondo de Cultura Económica (FCE). 
Noris Evelin Duque Zambrano

e-mail: norisduquezambrano@gmail.com

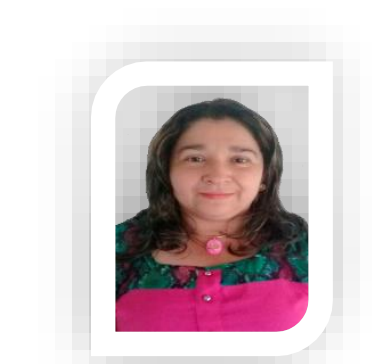

Nací en la Ciudad de el Vigía, Estado Mérida, Venezuela, el 03 de octubre de 1973. Trabajo en la Universidad Nacional Experimental Simón Rodríguez (UNESR). Soy Licenciada en Administración, Magíster en Administración Mención Mercadeo y en Educación Robinsoniana. Profesora Agregada a Tiempo Completo, docente e investigadora de la UNESR, EI Vigía, Venezuela.

El contenido de este manuscrito se difunde bajo una Licencia de Creative Commons ReconocimientoNoComercial-Compartirlgual 4.0 Internacional 